\title{
Post-COVID-19 ergonomic school furniture design under fuzzy logic
}

\author{
Cetin O. Incekara \\ BOTAS, Transit Pipeline Manager, Ankara, Turkey \\ ORCID: 0000-0003-1927-8208; E-mail: cetinincekara@ gmail.com.
}

Received 26 April 2021

Accepted 13 May 2021

\begin{abstract}
.
BACKGROUND: Because of wrong sitting position, children have back-pain and related musculoskeletal pain (MPD). Due to inappropriate designed class furniture by not taking into account the children's anthropometric measurements have negative effect on children musculoskeletal systems. The impact of the COVID-19 pandemic crisis has changed the furniture industry's production trends.

OBJECTIVE: This study aimed to develop a new fuzzy based design of ergonomic-oriented classroom furniture for primary school students considering the measured anthropometric dimensions of students' safety, health, well-being, i.e. ergonomic criteria, socio-psychological aspect and post-COVID policies.

METHODS: In the study 2049 number of primary school students are assessed considering COVID-19 pandemic policies and their static anthropometric dimensions were measured between 7-10-year-old (between 1st-4th grade students) and descriptive statistics of children among their ages and genders are calculated; mean, standard deviation, percentiles. The data collected from the students were analyzed quantitatively by using Significance Analysis: Mann-Whitney U test statistic, $t$-test, Regression Analysis and one-way ANOVA. In the study interviews with experts are performed and fuzzy mathematical model (by using fuzzy-AHP, fuzzy-TOPSIS and fuzzy-VIKOR) is developed to calculate Turkey's three schools' furniture. RESULTS: Results showed statistically significant differences between two genders. And it is observed that the seating bench height is too high for primary school students and lower than the height of the classroom's blackboard from the floor. Fuzzy Multi Criteria Decision Making Method's (FMCDM) results show that primary school students' ergonomic classroom furniture should be mainly designed by considering "COVID-19 Criteria", "Ergonomic Criteria" and "Socio-Psychological Aspect”. Students' existing seating benches and tables are changed by considering post-COVID policies/protocols, Ergonomic Criteria and Socio-Psychological Aspect. And a new seating bench/chair and table's dimensions is proposed in the study.

CONCLUSIONS: Children study at school for long periods and their activities involve long periods of time on their desks in schools. As per the results of the study, it can be concluded that school management must consider the genders, ages of students and take into account the post-COVID policies/protocols while procuring the classroom furniture. The COVID-19 pandemic is the single largest event to have affected children globally in their access to school in recent times; estimates suggest that over $85 \%$ of the world's total enrolled learners, 1.5 billion children and youths, have been affected. The coronavirus pandemic also creates dramatic changes for the school furniture.
\end{abstract}

Keywords: Ergonomic design, school furniture, students, fuzzy logic, fuzzy AHP/TOPSIS/VIKOR, COVID

\section{Introduction}

Furniture designs change over time taking into account ergonomics and anthropometric data. By the mid-19th century, the industrial revolution and the impact of mass production enabled the production of chairs and tables in various forms [1]. The chairs were depicted with a low seat as seen on Egyptian Pharaohs' stools [2]. Ergonomics and anthropometry have been used to combine adjustability to accommodate a wider range of people, to develop new forms of furniture that include task/office tables/chairs [3]. 
Although adjustability was the primary criteria in furniture designs, the adjustable furniture has beed used in 1960s. In the early 1990s, many furniture manufacturers start to mass furniture production based on measured anthropometric data [4].

The design of school furniture is not focused by manufacturers until recent years. School furniture's design should be based on anthropometry and ergonomic criteria. But they are not focused on the statistics and anthropometric data/measurements, i.e. gender, nationality, body structure, age, physical activity, nutrition.

The impact of the COVID-19 pandemic crisis has changed the furniture industry's production trends and increased the importance of digitalization. Social distancing has become the new normal after the COVID-19 pandemic, therefore consumers' and school management spending on school furniture is expected to increase.

Many researchers make investigations on prolonged sitting and the design of chair, desk and their combinations in work place and computer workstation [5-9]. Few researchers have been investigated and proposed ergonomic-oriented classrooms' furniture designs [10-12], this study investigates school furniture and recommend school furniture design guideline considering the measured anthropometric dimensions of students and post-COVID policies/protocols.

\section{Aim of the study}

The main goal of the study is to recommend the ergonomics oriented system based on Student Health framework for school managers. The new ergonomic school furniture design protects students' health, and well-being in post-COVID period. To design a post-COVID ergonomic classroom furniture, first step is to examine the existing school furniture dimensions [13, 14] if they are well-matched to students' anthropometric measurements.

The results obtained from the investigation (in fall semester of 2019-2020) show that in pre-COVID period children attended classes regularly, i.e. five times a week, and were seated more than five hours in a day. In contrast, in the post-COVID period, children attended classes irregularly, i.e. maximum two times a week, and were seated more than five hours a day when they attended their classes.

\section{Previous studies about school furniture}

In the literature there are few studies about school furniture designs. Many studies showed that children were seated long periods in classrooms [9, 15-17] and this causes bone and muscle pain. Sitting for a long time in wrong position causes illness, such as low back pain [18]. Students' back pain and neck pain problems have been frequently seen among students [19]. Numerous researches investigated prolonged sitting on the chairs/furniture $[8,9,20,21]$.

All over the world due to unsuitable school furniture designs; children are under the severe risk of musculoskeletal injuries in schools, i.e. postural stresses and strains due to prolonged sitting [22, 23]. Continuous sitting position has disadvantages, and potential long-term consequences.

The correct determination of the classroom furniture dimensions is only valid if anthropometric measurements of the students are taken correctly [24]. And it is related with the correct/proper sitting postion [25-27]. Saarni et al. [2] investigated the children sitting postures positions which affect their spine while working on computer workstation. They proposed new ergonomic classroom furniture to reduce musculoskeletal disorders and pain that students experienced. In the literature there is not any ergonomic classroom furniture study considering post-COVID policies and protocols.

\section{Material and methods}

Governments and non-governmental organizations provide resources to create safer and supportive environments to organizations [28]. Due to the COVID-19 pandemic, many countries closed their schools, around 1.6 billion students continue their education via distance-learning system.

While developing post-COVID classroom furniture, it is necessary to get the students' anthropometric measurements considering their gender, nationality, body structure, age, physical activity, nutrition. In the study three primary schools in Turkey were investigated, and the details of them are presented in Table 1.

While measuring the students' anthropometric measurements, standard anthropometric measurements were used and measured by using ISO and EN-standards, i.e. ISO 5970-1979 and EN1729. The following anthropometric dimensions of primary school students (weight; sitting height; eye, elbow, 
Table 1

Investigated student numbers in Turkey

\begin{tabular}{|c|c|c|c|c|c|c|}
\hline \multirow[b]{2}{*}{$\underline{\text { Student number }}$} & \multicolumn{2}{|c|}{ School A } & \multicolumn{2}{|c|}{ School B } & \multicolumn{2}{|c|}{ School C } \\
\hline & Boys & Girls & Boys & Girls & Boys & Girls \\
\hline 1st class & 74 & 69 & 71 & 70 & 98 & 93 \\
\hline 2nd class & 81 & 79 & 87 & 84 & 89 & 91 \\
\hline 3rd class & 93 & 91 & 83 & 82 & 97 & 91 \\
\hline 4th class & 89 & 85 & 91 & 83 & 92 & 86 \\
\hline Total: & 337 & 324 & 332 & 319 & 376 & 361 \\
\hline
\end{tabular}

shoulder, elbow, knee height, arm length; elbowelbow distance; shoulder... ) which are necessary to design the chair, desk, table and seating benches, i.e. school furniture, were taken/measured as per related ISO and EN standards.

Students' weight and height measurements in examined three Turkish primary schools are presented in Table 2 and Table 3. Students' seating benches width measurements in examined three Turkish primary schools are presented in Table 4.

\subsection{Methods used in the study}

In the study; an integrated Fuzzy-AHP FuzzyTOPSIS and Fuzzy-VIKOR approaches are used to assess/evaluate Turkey's primary students' ergonomic classroom furniture. In literature Fuzzy Multi Criteria Decision Making Methods (FMCDM) are used in different fields by many researchers and Fuzzy-AHP, Fuzzy-TOPSIS and Fuzzy-VIKOR are also used in many sectors/researches [29-36]. In this study Turkey's primary school students' ergonomic classroom furniture design considering post-COVID policies and protocols is performed under fuzzy logic.

\subsubsection{Fuzzy-AHP method}

Since the standard AHP method does not include the possibility of situations with ambiguity in the estimation, it is possible to upgrade this method with fuzzy approach, i.e. Fuzzy-AHP method. The FuzzyAHP method suggests their application directly in criteria pairs comparison matrix. Triangular fuzzy numbers are used in most cases/problems by many researchers in literature because of this reason in the study triangular fuzzy numbers method is used in Fuzzy-AHP method. A triangular fuzzy number that is defined in $R$ set can be described as $\tilde{N}=(1, n$, $\mathrm{u}$ ) where 1 is the minimum, $\mathrm{n}$ is the most possible and $u$ is the maximum value of a fuzzy case. Its triangular membership function is characterized below [37] which is presented in Fig. 1 and in equation (1) [31-33].

$$
\mu \tilde{N}(\mathrm{x})=\left\{\begin{array}{c}
(x-l) /(n-l), l \leq x \leq n \\
(x-u) /(n-u), n \leq x \leq u \\
0, x\langle l \text { or } x\rangle u
\end{array}\right.
$$

In the study the performance of each scenario to each criterion is introduced as a fuzzy number. And in the study the ratings of qualitative criteria are considered as linguistic variables. These linguistic variables can be expressed in positive triangular fuzzy numbers as described in Table $5[29,30]$.

After forming a matrix of fuzzy criteria comparison it should be defined vector of criteria weights W.

Table 2

Students' weight measurements $(\mathrm{kg})$

\begin{tabular}{lccccc}
\hline Class & $\begin{array}{c}\text { Total } \\
\text { student } \\
\text { numbers }\end{array}$ & $\begin{array}{c}\text { Average } \\
(\mathrm{kg})\end{array}$ & $\begin{array}{c}\text { Standard } \\
\text { deviation } \\
( \pm)\end{array}$ & Minimum & Maximum \\
\hline 1st class & 475 & 24,64 & 2,76 & 17,6 & 34,9 \\
2nd class & 511 & 28,49 & 4,97 & 17,1 & 43,7 \\
3rd class & 537 & 31,97 & 7,19 & 22,8 & 56,5 \\
4th class & 526 & 34,93 & 6,41 & 23,6 & 58,9 \\
\hline
\end{tabular}

Table 3

Students' height measurements $(\mathrm{cm})$

\begin{tabular}{lccccc}
\hline Class & $\begin{array}{c}\text { Total } \\
\text { student } \\
\text { numbers }\end{array}$ & $\begin{array}{c}\text { Average } \\
(\mathrm{cm})\end{array}$ & $\begin{array}{c}\text { Standard } \\
\text { deviation } \\
( \pm)\end{array}$ & Minimum & Maximum \\
\hline 1st class & 475 & 119,95 & 5,38 & 101 & 137 \\
2nd class & 511 & 128,96 & 5,94 & 114 & 142 \\
3rd class & 537 & 134,07 & 6,13 & 116 & 159 \\
4th class & 526 & 141,91 & 7,01 & 118 & 169 \\
\hline
\end{tabular}


Table 4

Students' seating bench width measurements $(\mathrm{cm})$

\begin{tabular}{lccccc}
\hline Class & $\begin{array}{c}\text { Total } \\
\text { student } \\
\text { numbers }\end{array}$ & $\begin{array}{c}\text { Average } \\
(\mathrm{cm})\end{array}$ & $\begin{array}{c}\text { Standard } \\
\text { deviation } \\
( \pm)\end{array}$ & Minimum & Maximum \\
\hline 1st class & 475 & 25,07 & 2,01 & 21 & 32 \\
2nd class & 511 & 26,13 & 2,14 & 21 & 33 \\
3rd class & 537 & 26,14 & 3,41 & 22 & 33 \\
4th class & 526 & 27,97 & 3,94 & 23 & 34 \\
\hline
\end{tabular}

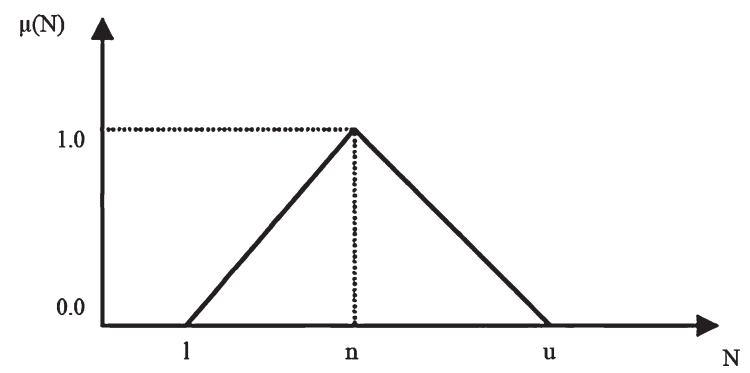

Fig. 1. Triangular fuzzy number.

For that purpose, the following equations/steps were used in the study.

Let $X=\{\mathrm{x} 1, \mathrm{x} 2, \ldots, \mathrm{xm}\}$ be an object set, and $G=\{\mathrm{g} 1, \mathrm{~g} 2, \ldots, \mathrm{gn}\}$ be a goal set. N extent analysis values for each object can be obtained as $\mathrm{N}_{g i}^{1}, \mathrm{~N}_{g i}^{2}, \ldots$, $\mathrm{N}_{g i}^{n} i=1,2, \ldots \mathrm{n}$

Step 1: The values of fuzzy extensions for the i-th object are given in Expression (2);

$$
S i=\sum_{\mathrm{j}=1}^{n} \mathrm{~N}_{g i}^{j} \otimes\left[\sum_{i=1}^{m} \sum_{j=1}^{n} \mathrm{~N}_{g i}^{j}\right]^{-1}
$$

In order to obtain the expression $\left[\sum_{i=1}^{m} \sum_{j=1}^{n} \mathrm{~N}_{g i}^{j}\right]$ it is necessary to perform additional fuzzy operations with $\mathrm{n}$ values of the extent analysis, which is represented in Equation (3) and (4);

$$
\begin{gathered}
\sum_{\mathrm{j}=1}^{n} \mathrm{~N}_{g i}^{j}=\left(\sum_{j=1}^{n} \mathrm{lj}, \sum_{j=1}^{n} \mathrm{nj}, \sum_{j=1}^{n} \mathrm{uj}\right) \\
{\left[\sum_{i=1}^{m} \sum_{j=1}^{n} \mathrm{~N}_{g i}^{j}\right]=\left(\sum_{i=1}^{m} \mathrm{li}, \sum_{i=1}^{m} \mathrm{ni}, \sum_{i=1}^{m} \mathrm{ui}\right)}
\end{gathered}
$$

And it is required to calculate the inverse vector above by using Expression (5);

$$
\left[\sum_{i=1}^{m} \sum_{j=1}^{n} \mathrm{~N}_{g i}^{j}\right]^{-1}=\left(\frac{1}{\sum_{i=1}^{m} \mathrm{ui}}, \frac{1}{\sum_{i=1}^{m} \mathrm{ni}}, \frac{1}{\sum_{i=1}^{m} \mathrm{li}}\right)
$$

Step 2: While $\mathrm{N}_{1}$ and $\mathrm{N}_{2}$ are triangular fuzzy numbers, the degree of possibility for $\mathrm{N}_{2} \geq \mathrm{N}_{1}$ is defined as:

$$
\mathrm{V}\left(\mathrm{N}_{2} \geq \mathrm{N}_{2}\right)=\sup _{\mathrm{y} \geq \mathrm{x}}\left(\min \left(\mu \mathrm{N}_{1}(x), \mu \mathrm{N}_{2}(y)\right)\right)
$$

It can be represented in the following manner by Expression (7):

$$
\begin{aligned}
& \mathrm{V}\left(\mathrm{N}_{2} \geq \mathrm{N}_{1}\right)=\operatorname{hgt}\left(\mathrm{N}_{2} \cap \mathrm{N}_{1}\right) \mu \mathrm{N}_{2}(\mathrm{~d}) \\
& =\left\{\begin{array}{cc}
1, & \text { if } n_{2} \geq n_{1} \\
0, & \text { if } l_{1} \geq l_{2} \\
\frac{\left(l_{1}-u_{2}\right)}{\left(n_{2}-u_{2}\right)\left(m_{1}-l_{1}\right)}, & \text { otherwise }
\end{array}\right.
\end{aligned}
$$

Where $d$ is the ordinate of the highest intersection point $\mathrm{D}$ between $\mu \mathrm{N}_{1}$ and $\mu \mathrm{N}_{2}$.

Table 5

Linguistic variables for the alternatives

\begin{tabular}{lcc}
\hline Linguistic terms-abbreviation & Linguistic variables & Triangular fuzzy numbers \\
\hline SDA & Strongly disagree & $(0,0,0.15)$ \\
DA & Disagree & $(0.15,0.15,0.15)$ \\
LDA & Slightly disagree & $(0.30,0.15,0.20)$ \\
NC & No comment & $(0.50,0.20,0.15)$ \\
LA & Slightly agree & $(0.65,0.15,0.15)$ \\
A & Agree & $(0.80,0.15,0.20)$ \\
SA & Strongly agree & $(1,0.20,0)$ \\
\hline
\end{tabular}


To compare $\mu N_{1}$ and $\mu N_{2}$, values of both, $\mathrm{V}\left(\mathrm{N}_{2} \geq \mathrm{N}_{1}\right)$ and $\mathrm{V}\left(\mathrm{N}_{1} \geq \mathrm{N}_{2}\right)$ are needed.

Step 3: The degree of possibility for a convex fuzzy number to be greater than $\mathrm{k}$ convex numbers $\mathrm{Ni}(i=1,2, \ldots, \mathrm{k})$ can be defined by Expression (9);

$$
\begin{aligned}
& \mathrm{V}\left(\mathrm{N} \geq \mathrm{N}_{1}, \mathrm{~N}_{2}, \ldots, \mathrm{N}_{\mathrm{k}}\right) \\
& =\mathrm{V}\left[\left(\mathrm{N} \geq \mathrm{N}_{1}\right),\left(\mathrm{N} \geq \mathrm{N}_{2}\right)\right] \\
& =\min \mathrm{V}\left(\mathrm{N} \geq \mathrm{N}_{\mathrm{i}}=1,2,3, \ldots, \mathrm{k}\right)
\end{aligned}
$$

Assume that Expression (10) is;

$$
d^{\prime}\left(A_{\mathrm{i}}\right)=\min V\left(S_{\mathrm{i}} \geq S_{\mathrm{k}}\right)
$$

for $\mathrm{k}=1,2, \ldots, \mathrm{n} ; \mathrm{k} \neq \mathrm{i}$. So the weight vector is obtained by Expression (11);

$$
W^{\prime}=\left(d^{\prime}\left(A_{1}\right), d^{\prime}\left(A_{2}\right), \ldots, d^{\prime}\left(A_{m}\right)\right)^{T}
$$

where, $\mathrm{A}_{\mathrm{i}}(i=1,2, \ldots, \mathrm{n})$ consists of $\mathrm{n}$ elements.

Step 4: Through normalization, the weight vectors are reduced to Expression (12);

$$
W=\left(d\left(A_{1}\right), d\left(A_{2}\right), \ldots, d\left(A_{n}\right)\right)^{T}
$$

where $\mathrm{W}$ represents an absolute number [29-31].

\subsubsection{Fuzzy-TOPSIS method}

The fuzzy-TOPSIS calculation most important step is given in Expression (13) [38], i.e. Creating the Decision Matrix; aggregated ratings are calculated by using Equation (13) [29, 30]:

$$
\tilde{\mathrm{v}}_{\mathrm{ij}}=\frac{1}{2}\left[\tilde{\mathrm{v}}_{\mathrm{ij}}^{1} \oplus \tilde{\mathrm{v}}_{\mathrm{ij}}^{2} \oplus \ldots \tilde{\mathrm{v}}_{\mathrm{ij}}^{\mathrm{s}}\right]
$$

where $\tilde{v}_{\mathrm{ij}}^{\mathrm{s}}$ is the performance rating value obtained from s-th decision maker.

The basic steps of proposed fuzzy TOPSIS method can be described as follows [29-31]:

Step 1: In the first step, a panel of decision makers (DMs) who are knowledgeable about supplier selection process is established. In a group that has $\mathrm{K}$ decision-makers (i.e. D1, D2,..., Dk) are responsible for ranking (yjk) of each criterion (i.e. C1, C2, .. , $\mathrm{Cn}$ ) in increasing order. Then, the aggregated fuzzy importance weight for each criterion can be described as fuzzy triangular numbers $\tilde{\mathrm{v}}_{j}=\left(\mathrm{a}_{\mathrm{j}}, \mathrm{b}_{\mathrm{j}}, \mathrm{c}_{\mathrm{j}}\right)$ for $K=1$, $2, \ldots, \mathrm{K}$ and $j=1,2, \ldots, \mathrm{n}$. The aggregated fuzzy importance weight can be determined as follows:

$\mathrm{d}_{\mathrm{j}}=\min _{k}\left\{\mathrm{y}_{\mathrm{jk}}\right\}, \mathrm{b}_{\mathrm{j}}=\frac{1}{k} \sum_{k=1}^{K} y_{j k}, \mathrm{c}_{\mathrm{j}}=\max _{k}\left\{y_{j k}\right\}$
Then, the aggregated fuzzy importance weight for each criterion is normalized as follows: $\tilde{\mathrm{v}}_{j}=\left(\mathrm{a}_{\mathrm{j} 1}, \mathrm{~b}_{\mathrm{j} 2}\right.$, $\left.c_{j 3}\right)$

$$
\begin{aligned}
& \text { where } \mathrm{v}_{\mathrm{j} 1}=\frac{\frac{1}{d j}}{\sum_{j=1}^{n} \frac{1}{d j}}, v_{\mathrm{j} 2}=\frac{\frac{1}{b j}}{\sum_{j=1}^{n} \frac{1}{b j}}, \\
& v_{\mathrm{j} 3}=\frac{\frac{1}{c j}}{\sum_{j=1}^{n} \frac{1}{c j}}
\end{aligned}
$$

Then, the aggregated fuzzy importance weight for each criterion is normalized as follows: $\tilde{\mathrm{v}}_{j}=\left(\mathrm{a}_{\mathrm{j} 1}, \mathrm{~b}_{\mathrm{j} 2}\right.$, $\left.\mathrm{c}_{\mathrm{j} 3}\right)$

$$
\text { where } \mathrm{v}_{\mathrm{j} 1}=\frac{\frac{1}{d j}}{\sum_{j=1}^{n} \frac{1}{d j}}, \mathrm{v}_{\mathrm{j} 2}=\frac{\frac{1}{b j}}{\sum_{j=1}^{n} \frac{1}{b j}}, \mathrm{v}_{\mathrm{j} 3}=\frac{\frac{1}{c j}}{\sum_{j=1}^{n} \frac{1}{c j}}
$$

Then the normalized aggregated fuzzy importance weight matrix is constructed as $\tilde{\mathrm{v}}=\left(\tilde{\mathrm{v}}_{1}, \tilde{\mathrm{v}}_{2}, \ldots, \tilde{\mathrm{v}}_{\mathrm{n}}\right)$

Step 2: A decision matrix is formed.

$$
\mathrm{X}=\left[\begin{array}{cccc}
x 11 & x 12 & \ldots & x 1 n \\
x 21 & x 22 & \ldots & x 2 n \\
\ldots & \ldots & \ldots & \ldots \\
x m 1 & x m 2 & \ldots & x m n
\end{array}\right]
$$

Step 3: After forming the decision matrix, normalization is applied. The calculation is done using equations 18 and 19.

$\mathrm{r}_{\mathrm{ij}}=\frac{\frac{1}{x i j}}{\sqrt{\sum_{i=1}^{m} \frac{1}{x i j^{2}}}}$ for minimization objective, where

$\mathrm{i}=1,2, \ldots, \mathrm{m}$ and $\mathrm{j}=1,2, \ldots, \mathrm{n}$

$\mathrm{r}_{\mathrm{ij}}=\frac{x i j}{\sqrt{\sum_{i=1}^{m} x i j^{2}}}$ for maximization objective,

where $\mathrm{i}=1,2, \ldots, \mathrm{m}$ and $\mathrm{j}=1,2, \ldots, \mathrm{n}$

Then, normalized decision matrix is obtained as:

$$
\mathrm{R}=\left[\begin{array}{cccc}
r 11 & r 12 & \ldots & r 1 n \\
r 21 & r 22 & \ldots & r 2 n \\
\ldots & \ldots & \ldots & \ldots \\
r m 1 & r m 2 & \ldots & r m n
\end{array}\right]
$$

Step 4: Considering the different weights of each criterion, the weighted normalized decision matrix is computed by multiplying the importance weight of evaluation criteria and the values in the normalized 
decision matrix. The weighted normalized decision matrix $\tilde{\mathrm{v}}$ for each criterion is defined as:

$$
\tilde{\mathrm{v}}=\left[\tilde{\mathrm{v}}_{i j}\right]_{\mathrm{mxn}} \text { for } i=1,2, \ldots, \mathrm{m} \text { and } \mathrm{j}=1,2, \ldots, \mathrm{n}
$$

Where $\tilde{\mathrm{v}}_{i j}=r_{\mathrm{ij}} \mathrm{X} \tilde{\mathrm{O}}_{j}$

Here $\tilde{\mathrm{v}}_{i j}$ denotes normalized positive triangular fuzzy numbers.

Step 5: Then fuzzy positive ( $\left.\tilde{\mathrm{A}}^{*}\right)$ and fuzzy negative $\left(\tilde{\mathrm{A}}^{-}\right)$ideal solutions are determined as follows:

$$
\begin{gathered}
\tilde{\mathrm{A}}^{*}=\left(\tilde{\mathrm{v}}_{1}^{*}, \tilde{\mathrm{v}}_{2}^{*}, \ldots, \tilde{\mathrm{v}}_{\mathrm{n}}^{*}\right) \text { where } \\
\tilde{\mathrm{v}}_{\mathrm{j}}^{*}=\left\{\max _{\mathrm{i}}\left(v_{i j 1}\right), \max _{\mathrm{i}}\left(v_{i j 2}\right), \max _{\mathrm{i}}\left(v_{i j 3}\right)\right\} \text { and } \\
\tilde{\mathrm{A}}^{-}=\left(\tilde{\mathrm{v}}_{1}^{-}, \tilde{\mathrm{v}}_{2}^{-}, \ldots, \tilde{\mathrm{v}}_{\mathrm{n}}^{-}\right) \text {where } \\
\tilde{\mathrm{v}}_{\mathrm{j}}^{*}=\left\{\min _{\mathrm{i}}\left(v_{i j 1}\right), \min _{\mathrm{i}}\left(v_{i j 2}\right), \min _{\mathrm{i}}\left(v_{i j 3}\right)\right\} \\
\text { for } i=1,2, \ldots, \mathrm{m} \text { and } j=1,2, \ldots, \mathrm{n}
\end{gathered}
$$

Step 6: Then the fuzzy distance of each alternative from fuzzy positive and fuzzy negative ideal solutions are calculated as:

$$
\begin{aligned}
& \tilde{a}_{i}^{*}=\sqrt{\sum_{j=1}^{n}\left(\tilde{\mathrm{v}}_{j}^{*}-\tilde{\mathrm{v}}_{i j}^{*}\right)} \text { and } \\
& \tilde{a}_{i}^{-}=\sqrt{\sum_{j=1}^{n}\left(\tilde{\mathrm{v}}_{j}^{-}-\tilde{\mathrm{v}}_{i j}^{-}\right)} i=1,2, \ldots, m
\end{aligned}
$$

Step 7: Then the fuzzy closeness coefficient $\tilde{N}$ is determined as:

$$
\tilde{\mathrm{N}}_{\mathrm{i}}=\frac{\tilde{\mathrm{a}}_{\mathrm{i}}^{-}}{\tilde{\mathrm{a}}_{\mathrm{i}}^{*}+\tilde{\mathrm{a}}_{\mathrm{i}}^{-}} i=1,2, \ldots, \mathrm{m}
$$

The fuzzy closeness represents the distances to the fuzzy positive ideal solution and the fuzzy negative ideal solution simultaneously.

Step 8: The fuzzy closeness coefficient defuzzified as follows:

$$
\mathrm{N}_{\mathrm{i}}=\sqrt[3]{N_{i 1} \cdot N_{i 2} \cdot N_{i 3}}
$$

\subsubsection{Fuzzy-VIKOR method}

The VIKOR method is one of the FMCDM. It was developed by Serafim Opricovic [39] to solve decision problems with conflicting and noncommensurable criteria, assuming that compromise is acceptable for conflict resolution. VIKOR ranks alternatives and determines the compromise solution closest to the ideal solution. The international recognition of the VIKOR method was due to contribution of Serafim Opricovic and Gwo-Hshiung Tzeng [40].

In this study Fuzzy-VIKOR method is used to solve problem in a triangular hesitant fuzzy environment. The triangular fuzzy numbers are used to handle imprecise numerical quantities. FuzzyVIKOR is based on the aggregating fuzzy merit that represents distance of an alternative to the ideal solution [32]. The related steps are as follows [32]:

Step-1: Determine the positive triangular ideal solution (PTIS) and the negative triangular ideal solution (NTIS).

$$
\begin{gathered}
\mathrm{A}^{+}=\left\{f_{1}^{+}, f_{2}^{+}, \ldots, f_{n}^{+}\right\} \text {where } \\
f_{j}^{+}=\cup_{i=1}^{m} f_{i j}=\cup_{y 1 j \in \mathrm{f} 1 \mathrm{j} \ldots \mathrm{ymj} \in \mathrm{fmj}} \\
\left(\max \left(\gamma_{1 j}^{\mathrm{L}}, \ldots, \gamma_{m j}^{\mathrm{L}}\right), \max \left(\gamma_{1 j}^{\mathrm{M}}, \ldots, \gamma_{m j}^{\mathrm{M}}\right),\right. \\
\left.\max \left(\gamma_{1 j}^{\mathrm{U}}, \ldots, \gamma_{m j}^{\mathrm{U}}\right)\right) \\
\mathrm{A}^{-}=\left\{f_{1}^{-}, f_{2}^{-}, \ldots, f_{n}^{-}\right\} \text {where } \\
f_{j}^{-}=\cap_{i=1}^{m} f_{i j}=\cap_{y 1}{ }_{j \in \mathrm{f} 1 \mathrm{j} \ldots \mathrm{ymj} \in \mathrm{fmj}} \\
\left(\min \left(\gamma_{1 j}^{\mathrm{L}}, \ldots, \gamma_{m j}^{\mathrm{L}}\right), \min \left(\gamma_{1 j}^{\mathrm{M}}, \ldots, \gamma_{m j}^{\mathrm{M}}\right),\right. \\
\left.\min \left(\gamma_{1 j}^{\mathrm{U}}, \ldots, \gamma_{m j}^{\mathrm{U}}\right)\right)
\end{gathered}
$$

Step-2: The aggregated fuzzy ratings of alternatives with respect to criterion are calculated by using below $\mathrm{Sj}$ and $\mathrm{Rj}$ below equations:

$$
\begin{gathered}
\tilde{\mathrm{S}}_{\mathrm{j}}=\sum_{j=1}^{n}\left[\tilde{w}_{\mathrm{i}}\left(\tilde{\mathrm{f}}_{\mathrm{i}}^{*}-\mathrm{xij}\right) /\left(\tilde{\mathrm{f}}_{\mathrm{i}}^{*}-\tilde{\mathrm{f}}_{\mathrm{i}}^{-}\right)\right] \\
\left.\tilde{\mathrm{R}}_{\mathrm{j}}=\max _{\mathrm{i}}\left[\tilde{w}_{\mathrm{i}} \tilde{\mathrm{f}}_{\mathrm{i}}^{*}-\mathrm{xij}\right) /\left(\tilde{\mathrm{f}}_{\mathrm{i}}^{*}-\tilde{\mathrm{f}}_{\mathrm{i}}^{-}\right)\right]
\end{gathered}
$$

where $\mathrm{w}_{\mathrm{i}}$ are the weights of the criteria expressing their relative importance.

Step-3: Normalization. Compute the values $\tilde{\mathrm{Q}}_{\mathrm{i}}$ by using below expressions:

$$
\begin{gathered}
\tilde{S}^{*}=\min _{i} \tilde{S}_{i}, \widetilde{S}^{-}=\max _{i} \tilde{S}_{i} \\
\tilde{R}^{*}=\min _{i} \tilde{R}_{i}, \tilde{R}^{-}=\max _{i} \tilde{R}_{i}
\end{gathered}
$$




$$
\tilde{\mathrm{Q}}_{\mathrm{i}}=v \frac{\tilde{\mathrm{S}}_{\mathrm{i}}-\tilde{\mathrm{S}}^{*}}{\left(\tilde{\mathrm{S}}^{-}-\tilde{\mathrm{S}}^{*}\right)}+(1-v)\left(\tilde{\mathrm{R}}_{\mathrm{i}}-\tilde{\mathrm{R}}^{*}\right) /\left(\tilde{\mathrm{R}}^{-}-\tilde{\mathrm{R}}^{*}\right)
$$

Step-4: Rank the alternatives by sorting the values of $\mathrm{S}, \mathrm{R}$ and $\mathrm{Q}$ in decreasing order which results in three ranking lists.

$$
\mathrm{BNP}_{\mathrm{i}}=\left[\left(\mathrm{u}_{\mathrm{i}}-1\right)+\left(\mathrm{m}_{\mathrm{i}}-\mathrm{l}_{\mathrm{i}}\right)\right] / 3+\mathrm{l}_{\mathrm{i}}
$$

Step-5: Propose as a compromise solution the alternative $A^{\prime}$ which is ranked the best by the measure $\mathrm{Q}$ (minimum) if the following two conditions are satisfied:

CC1: Acceptable advantage:

$\mathrm{Q}\left(\mathrm{A}^{\prime \prime}\right)-\mathrm{Q}\left(\mathrm{A}^{\prime}\right) \geq \mathrm{DQ}$

where $A$ " is the alternative with second position in the ranking list by $\mathrm{Q} ; \mathrm{DQ}=1 /(\mathrm{m}-1) \mathrm{DQ}=1 /(\mathrm{m}-1)$ (if $m \leq 5$ ise $\mathrm{DQ}=0.25$ ); where $\mathrm{m}$ is the number of alternatives.

CC2: Acceptable stability in decision: Alternative A" must also be the best ranked by S or/and R. This compromise solution is stable within a decision making process, which could be "voting by majority rule" (when $v>0.5$ is needed) or by "consensus" $\mathrm{v}$ $\approx 0.5$ or with "veto" $(v<0.5)$. Here $\mathrm{v}$ is the weight of the decision making strategy "the majority criteria" or ("maximum group utility"). If one of the two conditions is not satisfied, then a set ofcompromise solutions is proposed, which consists of:

- Alternatives A" and A' if only condition CC2 is not satisfied, or

- Alternatives $A^{\prime}, A^{\prime \prime} \ldots A^{m}$ if condition $\mathrm{CC} 1$ is not satisfied, $A^{m}$ is determined by the relation $\mathrm{Q}\left(\mathrm{A}^{\mathrm{m}}\right)-\mathrm{Q}\left(\mathrm{A}^{\prime}\right) \leq \mathrm{DQ}$ for maximum $\mathrm{m}$ (the positions of these alternatives are "in closeness").

In the study Fuzzy-AHP, Fuzzy-TOPSIS and Fuzzy-VIKOR procedures and related calculations have been coded/solved by using MATLAB program.

\subsubsection{Selection of Turkey's primary school students' ergonomic classroom furniture}

Turkey's primary school students' ergonomic classroom furniture, i.e. measuring scale, consists of 6 dimensions-main criteria and 18 evaluation factors-sub-criteria are evaluated/assessed by each expert/DM. In the process of prioritization of criteria, subcriteria and alternatives, the DMs used in the selection process was consulted. A questionnaire was developed following the methodology proposed
Table 6

Average seating bench width in one of the primary schools $(\mathrm{cm})$

\begin{tabular}{lc}
\hline & Average $(\mathrm{cm})$ \\
\hline Seating bench width & 23,41 \\
\hline
\end{tabular}

for the below methods, which was answered by 29 experts/DMs. The comparison matrix and pairwise comparison matrices for subcriteria and alternatives are calculated. Subsequently, the normalized pairwise comparison matrix of criteria was obtained. The priority vector and the $\mathrm{CR}$ for the criteria were obtained. In the study 6 main criteria and related sub-criteria are presented below:

C1. Technical Criteria: The criteria define the technical relevance of the ergonomic classroom furniture related issues to be implemented according to the scope established in the following subcriteria; i.e. students' ergonomic dimensions. Students' anthropometric measurements and related calculation of descriptive statistics (standard deviation, mean, and key percentiles: 5,50 , and 95 percentiles) were calculated (Table 6, Table 7, Table 9, Table 10, Table 12, Table 13). Students' $t$-test results (Table 8, Table 11, Table 14) and significance analysis (Mann-Whitney $\mathrm{U}$ test statistics) were calculated between two genders, in which a significant difference was found. Regression analysis and one-way ANOVA test were performed. It was observed that the seating bench height is too high for primary school students and lower than the height of the classroom's blackboard from the floor.

C2. Ergonomic Criteria: The ergonomic criteria allow for incorporation of the benefits and costs incurred in implementing the project, according to the scope established ISO and EN standards.

C3. COVID-19 Criteria: The COVID-19 pandemic has changed the educational system, and have to evolve to meet new challenges considering post-COVID policies and protocols. The related sub-criteria are; COVID-19 Protocols, Post-COVID Policies, Post-COVID Protocols, Physical Distance, Health Security Protocols.

C4. Socio-Psychological Aspect: It is one of the criteria of designing post-COVID school furniture. The related sub-criteria are; Public/Family Acceptance, Institutional Arrangement, post-COVID Regulatory Mechanism.

C5. Environmental Criteria: The environmental criteria incorporate the impact of the implementation of the school furniture, according to the scope established in the following subcriteria; Ambient Air 
Table 7

Sitting width averages of all students in one of the Turkish primary schools

\begin{tabular}{lccc}
\hline & N & Average $(\mathrm{cm})$ & Standard deviation $( \pm)$ \\
\hline Sitting width averages of students & 2049 & 24,83 & 4,95 \\
\hline
\end{tabular}

Table 8

One-sample test: Sitting width - T test chart

\begin{tabular}{lcccc}
\hline & \begin{tabular}{c} 
Test value $=23,41 \mathrm{~cm}$ \\
\cline { 2 - 4 }
\end{tabular} & df & Sig. (2-tailed) & $\begin{array}{r}\text { Average } \\
\text { difference }\end{array}$ \\
\hline Sitting width & 4,134 & 2049 & 0,000 & 1,1013 \\
\hline
\end{tabular}

Table 9

Seat height averages

\begin{tabular}{lc}
\hline & Average $(\mathrm{cm})$ \\
\hline Seating bench height & 37,26 \\
\hline
\end{tabular}

Pollution, Air Pollution Status of School, Exhaled Air Pollution, Hazardous Waste.

C6. Existing Furniture Condition Criteria: Since it will reduce the cost of school furniture expenses significantly. The related sub-criteria are; Condition/status of School Furniture, Maintenance Cost, Capacity Factor.

Determining the evaluation criteria weights with Fuzzy-AHP approach: Firstly, each DM practiced pair-wise comparisons of post-COVID school furniture design's dimensions and evaluation factors by using fuzzy-AHP. The pair-wise comparison values are converted to triangular fuzzy numbers and fuzzy pair-wise comparison matrices are created [29-33] and presented in Table 15.

$$
\mathrm{l}_{\mathrm{ij}}=\min _{\mathrm{k}} \mathrm{a}_{\mathrm{ijk}} \mathrm{n}_{\mathrm{ij}}=\frac{1}{\mathrm{~K}} \sum_{\mathrm{j}=1}^{\mathrm{K}} \mathrm{b}_{\mathrm{ijk}} \mathrm{u}_{\mathrm{ij}}=\max _{\mathrm{k}} \mathrm{c}_{\mathrm{ijk}}
$$

After acquiring the fuzzy comparison matrices, importance weights of school furniture design's dimensions; evaluation criteria is calculated by the FAHP method [29]. According to the calculated
Table 12

The average height of the classroom's blackboards/whiteboards from the floor

\begin{tabular}{lc}
\hline & Average $(\mathrm{cm})$ \\
\hline Height of the classroom's blackboard/whiteboard & 63,15 \\
from the floor & \\
\hline
\end{tabular}

criteria weights for schools' furniture weights; the most important evaluation dimension/main-criteria is "COVID-19 Criteria" with 0.216 importance weight, the second important evaluation dimension is "Ergonomic Criteria" with 0.207 importance weight and the third important evaluation dimension is "Socio-Psychological Aspect" with 0.173 importance weight.

Ranking the alternatives by using Fuzzy-TOPSIS and Fuzzy-VIKOR methods: To evaluate the school furniture, Fuzzy-TOPSIS and Fuzzy-VIKOR approaches are conducted with the collected data of DM's surveys/interviews. Primarily, the linguistic variables of the alternatives are created. By the help of criteria weights, Fuzzy-TOPSIS and FuzzyVIKOR method's steps are performed/completed and three schools' furniture are ranked. Primarily, the linguistic variables of the alternatives are created thusly in Table 16.

Then Fuzzy-TOPSIS method is used for the ranking of three schools' furniture according to the relative distance values of alternatives (CCi). The values of indicators are set into triangular fuzzy

Table 10

Knee height averages of all students in one of the Turkish primary schools

\begin{tabular}{lccc}
\hline & $\mathrm{N}$ & Average & Standard deviation $( \pm)$ \\
\hline Knee height averages of students & 2049 & 34,51 & 3,74 \\
\hline
\end{tabular}

Table 11

Knee height - T test chart

\begin{tabular}{lcccc}
\hline & \begin{tabular}{l} 
Test value $=37,26 \mathrm{~cm}$ \\
\cline { 2 - 4 }
\end{tabular} & df & Sig. (2-tailed) & $\begin{array}{c}\text { Average } \\
\text { difference }\end{array}$ \\
\hline Knee height & $-14,38$ & 2049 & 0,000 & $-2,1$ \\
\hline
\end{tabular}


Table 13

Eye height (sitting) averages of all students in one of the Turkish primary schools

\begin{tabular}{lccc}
\hline & $\mathrm{N}$ & Average & Standard deviation $( \pm)$ \\
\hline Eye height (sitting) averages of students & 2049 & 59,92 & 5,18 \\
\hline
\end{tabular}

Table 14

Eye height (sitting) - T test chart

\begin{tabular}{|c|c|c|c|c|}
\hline & $\frac{\text { Test value }=63,15 \mathrm{~cm}}{\mathrm{t}}$ & $\mathrm{df}$ & Sig. (2-tailed) & $\overline{\text { Average difference }}$ \\
\hline Eye height (sitting) & $-14,96$ & 2049 & 0,000 & $-3,11$ \\
\hline
\end{tabular}

Table 15

Fuzzy mutual criteria comparison

\begin{tabular}{lccccrr}
\hline & $\mathrm{C} 1$ & $\mathrm{C} 2$ & $\mathrm{C} 3$ & $\mathrm{C} 4$ & $\mathrm{C} 5$ & $\mathrm{C} 6$ \\
\hline $\mathrm{C} 1$ & $(1,1,1)$ & $(3,5,7)$ & $(3,5,7)$ & $(5,7,9)$ & $(7,9,11)$ & $(7,9,11)$ \\
$\mathrm{C} 2$ & $(1 / 7,1 / 5,1 / 3)$ & $(1,1,1)$ & $(3,5,7)$ & $(3,5,7)$ & $(7,9,11)$ & $(7,9,11)$ \\
$\mathrm{C} 3$ & $(1 / 7,1 / 5,1 / 3)$ & $(1 / 7,1 / 5,1 / 3)$ & $(1,1,1)$ & $(5,7,9)$ & $(7,9,11)$ & $(7,9,11)$ \\
$\mathrm{C} 4$ & $(1 / 9,1 / 7,1 / 5)$ & $(1 / 7,1 / 5,1 / 3)$ & $(1 / 9,1 / 7,1 / 5)$ & $(1,1,1)$ & $(1,7,9)$ & $(3,5,7)$ \\
C5 & $(1 / 11,1 / 9,1 / 7)$ & $(1 / 11,1 / 9,1 / 7)$ & $(1 / 11,1 / 9,1 / 7)$ & $(1 / 9,1 / 7,1)$ & $(1,1,1)$ & $(3,5,7)$ \\
C6 & $(1 / 11,1 / 9,1 / 7)$ & $(1 / 11,1 / 9,1 / 7)$ & $(1 / 11,1 / 9,1 / 7)$ & $(1 / 7,1 / 5,1 / 3)$ & $(1 / 7,1 / 5,1 / 3)$ & $(1,1,1)$ \\
\hline
\end{tabular}

Table 16

Linguistic variables of the alternatives in Fuzzy TOPSIS method

\begin{tabular}{lcccccc}
\hline $\begin{array}{l}\text { Criteria } \\
\text { sectors }\end{array}$ & C1 & C2 & C3 & C4 & C5 & C6 \\
\hline School-A & A & A & SA & SA & A & DA \\
School-B & A & SA & SA & SA & A & A \\
School-C & A & A & A & SA & A & SDA \\
\hline
\end{tabular}

numbers. Utilizing the method of triangular fuzzy numbers, the fuzzy numbers of financial ratios are obtained [29-31]. After applying the steps in FuzzyTOPSIS method, i.e. defined steps in above Section, schools' performance scores are ranked. The ranking of the alternatives is as follows: School-B (first ranked), School-A (second ranked), School-C (third ranked). The reason of it is in School-B's furniture design; COVID-19 criteria, ergonomic criteria and socio-psychological aspect criteria are considered/satisfied.

In Fuzzy-VIKOR method, by ranking the preference order by the help of DMs/experts and by compromise solution; School-B's furniture design is the best alternative. From the comparison table we find that the values of Q1 increases as the value of weight $v$ increases, the values of Q3 decreases as the value of weight $v$ increases while values of Q1 remains unaltered. The ranking of the alternatives is not affected by the change of weights.

\subsubsection{Post-COVID policies related to schools}

The COVID-19 pandemic has changed the educational system, related landscape, and learning- environments of students, i.e. schools, have to evolve to meet new challenges considering postCOVID policies and protocols stated by WHO-World Health Organization, CDC-Centers for Disease Control and Prevention, and recommendations during the COVID-19 pandemic [41-43]. In the post-COVID period, changes in physical spacing are required to allow physical distance between students. This can be achieved by using unused areas/spaces in classrooms and adding new elements to existing furniture, i.e. transparent shields, and the necessary areas/spaces to prevent the transmission of diseases, or purchase a new furniture that satisfy post-COVID policies, i.e. transparent shields ... etc.

Post-COVID strategies in schools include; redesigning larger unused spaces such as corridors, libraries and gyms, limiting classroom capacities, adding physical barriers between students, changing the configuration of desks in classrooms and their spacing should be arranged considering physical distancing (social distancing) guidelines, i.e. approx. 2 meters ( 6 feet).

When school educational system returns, the following improvements in schools should be made to keep every child safe in post-COVID period in schools:

- School's HVAC (Heating, Ventilating and Air Conditioning) air conditioning systems will be changed by higher filtering rate HVAC that have MERV 13 or MERV 17 filters. 
- School management should take precautions/measures on indoor air to reduce the spread of the COVID-19 pandemic, i.e. dilute the indoor air inside the school.

- Humidification systems similar to health systems in schools should be used in schools.

- Approx. $60 \mathrm{~cm} \mathrm{high,} \mathrm{transparent} \mathrm{table} \mathrm{top-}$ mounted screens on three sides of each classroom's tables/desks to provide shielding is added in post-pandemic period while maintaining site lines to classmates, teacher and content.

- A moveable screen provides a transparent shield between the teacher and students. It can be moved, if desired, to provide shielding while using the whiteboard.

- Landmarks, signs, colored tape marks on school's floor should be placed 2 meters apart to arrange/show physical distancing (social distancing).

\section{Conclusion}

Governments are setting comprehensive rules to prevent the spread of the COVID-19 pandemic. Due to the COVID-19 pandemic, standards are changing while adhering to healthcare standards covering COVID policies/protocols/precautions, the revised standards provide a healthy starting point for protecting students from the COVID-19 pandemic. Educational institutions should follow the above-mentioned revised standards and related recommendations to reduce the risk of COVID-19 transmission.

School furniture, i.e. an environmental factor, plays an important role in educational system since it affects the learning capacity of students, wheres it is often neglected. As people begin to develop posture patterns at an early age, the need for ergonomically designed furniture is a must to develop correct posture patterns and physical well-being in the future. School management provide an opportunity to improve student learning and participation capacities by purchasing suitable classroom furniture. While doing so, post-COVID policies and protocols stated in Section "Post-COVID Policies related to Schools" should be considered.

Due to improper designs of school furniture; children are under the severe risk of musculoskeletal injuries in schools. Examination of the existing school's furniture with the statistics/anthropometric measurements of children show that existing classroom desks and seating benches in the primary school are inappropriate furniture for the students.

In the study, fuzzy mathematical model (by using fuzzy-AHP/fuzzy-TOPSIS/fuzzy-VIKOR) is developed to calculate schools' furniture. Turkey's primary school students' ergonomic classroom furniture, i.e. measuring scale, consists of 6 dimensionsmain criteria; Technical Criteria, Ergonomic Criteria, COVID-19 Criteria, Socio-Psychological Aspect, Environmental Criteria, Existing Furniture Condition Criteria, and 18 evaluation factors-sub-criteria. In the process of prioritization of criteria, subcriteria and alternatives, the DMs used in the selection process was consulted. A questionnaire was developed following the methodology proposed for the below methods, which was answered by 29 experts/DMs.

In the study, firstly, each DM practiced pair-wise comparisons of Turkey's primary school students' ergonomic classroom furniture dimensions and evaluation factors are calculated by using fuzzy-AHP. Using the survey data acquired from these experts, integrated pair-wise comparison matrices are formed by combining all expert opinions. Thus, the pair-wise comparison values are converted to triangular fuzzynumbers and fuzzy pair-wise comparison matrices are created. After acquiring the fuzzy comparison matrices, importance weights of school furniture's dimensions; evaluation criteria is calculated by the FAHP method [29-32]. According to the calculated criteria weights for school furniture's weights; the most important evaluation dimension/main-criteria is "COVID-19 Criteria" with 0.216 importance weight, the second important evaluation dimension is "Ergonomic Criteria" with 0.207 importance weight and the third important evaluation dimension is "Socio-Psychological Aspect" with 0.173 importance weight.

In the study Fuzzy-TOPSIS and Fuzzy-VIKOR method is used for the ranking of three schools' furniture according to the relative distance values of alternatives. After applying the steps in FuzzyTOPSIS and Fuzzy-VIKOR method, i.e. defined steps in above Section, three schools' furniture performance scores are ranked. In Fuzzy-TOPSIS the ranking of the alternatives is as follows: School-B (first ranked), School-A (second ranked), School-C (third ranked). In Fuzzy-VIKOR method, by ranking the preference order and by compromise solution School-B's furniture design is the best alternative. The reason of the selection of School-B is; COVID-19 criteria, ergonomic criteria and socio-psychological 
Table 17

Proposed class room furniture dimensions for primary school students considering post-COVID policies/protocols (in $\mathrm{cm}$ )

\begin{tabular}{lcccc}
\hline Furniture dimensions $(\mathrm{cm})$ considering post-COVID policies & 1st grade & 2nd grade & 3rd grade & 4th grade \\
\hline Width of chairs & 31 & 32 & 33 & 34 \\
Width of desks & 40 & 40 & 41 & 42 \\
Height of chairs & 33 & 35 & 38 & 40 \\
Height of desks & 66 & 68 & 71 & 74 \\
Distance between desks and chairs & 6 & 1,80 & 1,90 & 1,90 \\
Distance between chairs considering post-COVID policies & 1,80 & &
\end{tabular}

aspect criteria are considered/satisfied in School-B's furniture design/selection.

FMCDM's results show that primary school students' ergonomic classroom furniture should be mainly designed by considering "COVID-19 Criteria", "Ergonomic Criteria" and "Socio-Psychological Aspect". Students' existing seating benches and tables are changed by consideing post-COVID policies/protocols, Ergonomic Criteria and SocioPsychological Aspect. If a new seating bench/chair and chair will be purchased by management than the chair dimensions proposed in Table 17 should be purchased or arranged accordingly.

The hesitant fuzzy environment when applied is very helpful in decision making situations when DM/experts might consider multiple priorities or judgments. All FMCDM methods estimate criteria weights by the help of DM so human judgment can be avoided by assigning weights to different attributes. In the study Fuzzy-AHP, Fuzzy-TOPSIS and FuzzyVIKOR approaches are conducted with the collected data of DM's surveys/interviews. Fuzzy-TOPSIS and Fuzzy-VIKOR methods result in same preference of selecting a school's furniture design based on Quality evaluation. Whereas fuzzy-VIKOR method stands out to be the best due to its computational easiness in the study.

With small changes to the density, geometry and division of the physical space in classrooms, the necessary physical distancing can be achieved in post-COVID period. This can be reached by rearranging the existing school furniture and adding a few new elements to classrooms' desks, tables and spaces. Bigger changes can be achieved by introducing more modular furniture and video technologies that maximize flexibility over time and can address the needs of multiple learning modes while maintaining distancing recommendations.

In the post-COVID period, physical distancing can be allowed by making changes in the physical spacing in schools. It can be made by adding few new items to existing furniture to prevent disease transmission, i.e. transparent shields, and using unused areas in school and classrooms, or purchase a new furniture that satisfy post-COVID policies which are explained/listed in above Section.

By applying the recommended new post-COVID ergonomics-oriented classroom furniture dimensions, comfort level of students satisfying postCOVID policies and protocols will increase and the new post-COVID design will reduce the musculoskeletal disorders, related pain and aches.

\section{Acknowledgments}

Special thanks to the schools' management for their help and support while investigating the school's furniture and measuring anthropometric dimensions of students.

\section{Conflict of interest}

None to report.

\section{References}

[1] Diep NB. Evaluation of Fitness between School Furniture and Children Body Size in Two Primary Schools in Haiphong. Master's Thesis. Vietnam. Lulea University of Technology. M.Sc. Programme in Indistrial Ergonomics. 2003;86.

[2] Saarni L, Nygård CH, Kaukiainen A, Rimpelä A. Are the desks and chairs at school appropriate? Ergonomics. 2007; 10:1561-70.

[3] Lueder R, Rice V. Ergonomics for Children: Designing products and places for toddler to teens. CRC Press. 2007; 14:329-39.

[4] Cranz G. The Alexander Technique in the world of design: posture and the common chair. J. Bodywork Movement Ther. 2000;4(2):90-8.

[5] Oyewole SA, Haight JM, Freivalds A. The ergonomic design of classroom furniture/computer work station for first graders in the elementary school. International Journal of Industrial Ergonomics. 2010;40(4):437-47. 
[6] Villanueva MB, Sotoyama M, Jonai H, Takeuchi Y, Saito S. Adjustments of posture and viewing parameters of the eye to changes in the screen height of the visual display terminal. Ergonomics. 1996;39(7):933-45.

[7] Wall MD, Riel MPJMV, Snijders CJ, Wingerden JPV. The effect on sitting posture of a desk with a $10^{\circ}$ inclination for reading and writing. Ergonomics. 1991;34:575-84.

[8] Cook CJ, Kothiyal K. Influence of mouse position on muscular activity in the neck, shoulder and arm in computer users. Appl. Ergonomics. 1998;29(6):439-43.

[9] Kumar S. A computer desk for bifocal lens wearers with special emphasis on selected telecommunication tasks. Ergonomics. 1994;37:1669-78.

[10] Tunay M, Melemez K. An analysis of biomechanical and anthropometric parameters on classroom furniture design. African Journal of Biotechnology. 2008;7(8):1081-6.

[11] Wickens CD, Lee JD, Liu Y, Becker SEG. An Introduction to Human Factors Engineering. 2nd. Upper Saddle River. NJ. USA. Pearson Education. 2004;184.

[12] Yarbrouh KA. The Relationship of School Design to Academic Achivement of Elemantary School Children. PhD Thesis. Department of Educational Leadership University. Georgia. 2001;86.

[13] Panagiotopoulou G, Christoulas K, Papanckolaou A, Mandroukas K. Classroom furniture dimensions and anthropometric measures in primary school. Applied Ergonomics. 2004;35(2):121-8.

[14] Milanese S, Grimmer K. School furniture and the user population: an anthropometric perspective. Ergonomics. 2004;47(4):416-26.

[15] Geldhof E, De Clercq D, De Bourdeaudhuij I, Cardon G. Classroom postures of 8-12 year old children. Ergonomics. 2007;50(10):1571-81.

[16] Linton SJ, Hellsing AL, Halme T, Akerstedt K. The effects of ergonomically designed school furniture on pupils' attitudes, symptoms and behaviour. Applied Ergonomics. 1994;5:299-304.

[17] Hedge A, Lueder R. Classroom furniture In: Ergonomics for Children: Designing Products and Places for Toddlers to Teens. Taylor \& Francis. New York. 2008;129.

[18] Troussier B, Davoine P, Gaudemaris R, Fauconnier J, Phelip X. Back pain in school children. A study among 1178 pupils. Scand.J. Rehabil. Med. 1994;26(3):143-54.

[19] Olsen TL, Anderson RL, Dearwater SR, Kriska AM, Cauley JA, Aaron DJ, LaPorte RE. The epidemiology of low back pain in an adolescent population. American Journal of Public Health. 1992;82(4):606-8.

[20] Leon LRP, Chaurand RA, Munoz ELG. Antropometric study of Mexican Primary School Children. Applied Ergonomics. 2001;(32):339-45.

[21] Incekara CO. Ergonomic school furniture design based on Turkish primary school students. 5th International Conference on Engineering Sciences (ICES). 19 September 2019. 2019;236.

[22] Mokdad M, Al-Ansari M. Anthropometrics for the design of Bahraini school furniture. Int. J. Indus. Ergonomics. 2009;39(5):728-35.

[23] Evans WA, Courtney AJ, Fok KF. The design of school furniture for Hong Kong school children: an anthropometric case study. Applied Ergonomics. 1988;19:122-34.

[24] Helander M. Anthropometry in workstation design In: Helander. A Guide to the Ergonomics of Manufacturing. Taylor \& Francis. London. 1997;17-28.

[25] Yeats B. Factors that may influence the postural health of school children (K-12). Work. 1997;9(1):45-55.
[26] Knight G, Noyes J. Children's Behaviour and Design of School Furniture. Ergonomics. 1999;42:747-60.

[27] Parcells C, Stommel M, Hubbard RP. Mismatch of classroom furniture and student body dimensions: empirical findings and health implications. Journal of Adolescent Health. 1999;24(4):265-73.

[28] OSHA. US Occupational Safety and Health Administration: Guidance on preparing workplaces for COVID-19. 2020. https://www.osha.gov/Publications/OSHA3990.pdf

[29] Incekara CO. Turkey 's natural gas demand projection in electricity generation. Journal of Turkish Operations Management. 2020;4(2):494-508.

[30] Incekara CO. Evaluation of Turkey's international energy projects by using Fuzzy Multi-Criteria Decision Making Methods. Euroasia Journal of Mathematics, Engineering Natural \& Medical Sciences. IEDSR. 2020;8(9):206-17.

[31] Incekara CO. Turkey's natural gas demand projections. EJONS International Journal On Mathematics, Engineering \& Natural Sciences. 2020;4(15):489-550.

[32] Incekara CO. ISO 50001 Energy Management System application in industrial sector with Fuzzy Logic. Afyon Kocatepe University Journal of Science and Engineering. 2020;20(6):991-1013.

[33] Incekara CO. Occupational Health and Safety Management System in one of the company operating in energy sector. Journal of Applied Sciences of Mehmet Akif Ersoy University. 2020;4(1):152-77.

[34] Incekara CO. Turkey's energy management plan by using fuzzy modelling approach. Scholars' Press. Book. 2019:3852.

[35] Incekara CO. Use of an Optimization Model for Optimization of Turkey's Energy Management by inclusion of Renewable Energy Sources. International Journal of Environmental Science and Technology. Springer. 2019;121-33.

[36] Incekara CO. Turkey and EU's energy strategies and policies. Journal of Turkish Operations Management. 2019;3(2):298-313

[37] Deng H. Multicriteria Analysis with Fuzzy Pairwise Comparison. International Journal of Approximate Reasoning. 1999;21:215-31.

[38] Song W, Ming X, Wu Z, Zhu B. Failure modes and effects analysis using integrated weight-based Fuzzy TOPSIS. International Journal of Computer Integrated Manufacturing. 2013;26:1172-86.

[39] Serafim O. Programski paket VIKOR za visekriterijumsko kompromisno rangiranje. SYMOPIS. 1990:267.

[40] Serafim O, Gwo-Hshiung T. The Compromise solution by MCDM methods: A comparativeanalysis of VIKOR and TOPSIS. European Journal of Operational Research. 2004;156(2):445-55.

[41] NIOSH. The National Institute for Occupational Safety and Health (NIOSH) Coronavirus Disease-2019. 2020. https://www.cdc.gov/niosh/emres/2019_ncov.html

[42] WHO. World Health Organization Coronavirus disease (COVID-19) technical guidance: Guidance for schools, workplaces \& institutions. 2020. https://www.who.int/ emergencies/diseases/novel-coronavirus-2019/technicalguidance/guidancefor-schools-workplaces-institutions

[43] CDC. Centers for disease control interim guidance for businesses and employers to plan and respond to coronavirus disease 2019 (COVID-19): Plan, prepare and respond to coronavirus disease 2019. 2020. https://www.cdc.gov/ coronavirus/2019-ncov/community/guidance-businessresponse.html 